\title{
Comprehensive Evaluation of Flood and Flood in the Yellow River Basin Based on Gray Correlation Analysis
}

\author{
Han Mo \\ Sichuan University, Chengdu, China \\ Email: mohan_97@163.com
}

How to cite this paper: Mo, H. (2021). Comprehensive Evaluation of Flood and Flood in the Yellow River Basin Based on Gray Correlation Analysis. Journal of Geoscience and Environment Protection, 9, 13-24. https://doi.org/10.4236/gep.2021.91002

Received: December 16, 2020

Accepted: December 31, 2020

Published: January 7, 2021

\begin{abstract}
Due to the concentrated rainfall and serious soil erosion in July and August in the Yellow River Basin, the flood discharge is not timely leading to serious floods. Therefore, a reasonable assessment of the flood-affected areas, advance arrangements for the deployment of the Yellow River basin flood disaster prevention and control plays a decisive role. For this purpose, this paper proposes a level assessment method based on the flood which analyzes three factors related to flooding disaster (disaster impact range, social index, and property index) through the gray correlation analysis method, to evaluate the level of flood disaster. Different from the traditional assessment method, which evaluates the nature of flood from the perspective of indicators such as frequency, duration, and magnitude, or indirect factors such as rainfall and soil loss, this paper conducts qualitative calculation of macro-scale indicators from the perspective of post-disaster losses in previous years. This study provides a new way of thinking and method for the classification of the flood disaster, which has certain practical application value under the condition of conforming to its own use.
\end{abstract}

\section{Keywords}

Flood Disaster, Gray Correlation Analysis, Flood Disaster Assessment, Comprehensive Post-Disaster Assessment

\section{Introduction}

In recent years, the development of the economy has caused irreversible damage to nature, leading to more and more serious flood disasters. China is one of the countries suffering the most serious floods in the world. According to statistics, 
from 2000 to 2018, the average annual flood disaster area in China reached $10,185.31$ thousand hectares, the average annual death rate was 1143 , and the direct economic losses reached 166,418.5 billion yuan (Press, 2019).

Floods are mainly caused by rainstorms, which are greatly affected by topography. Local rainstorms and floods occur every year, but large areas of rainstorms and floods occur less frequently. Flood heavy rain flood is a flood caused by heavy rainfall, which causes a rapid increase in river water and a sharp rise in water level. It is a necessary condition for flood formation. The characteristic of rainstorm and flood is an important parameter in flood analysis, and the occurrence and evolution of rainstorm are analyzed from the aspects of rainfall, topography, and landform. At present, China's existing flood catastrophe loss compensation methods mainly focus on national government compensation, social donation, insurance compensation, and a small range of flood bonds. In the face of the risks brought by flood and water catastrophe, the government's financial compensation ability is limited, and the government seems to be unable to cope with the catastrophe.

The main improvements have been in flood hazard assessment through improvements in assessment methods and models. A comprehensive modeling approach has been developed in the study of Kah Mun Wan and Lawal Billa, operating land imager (Oli) and thermal infrared sensor data, flood index and classification processes are used to estimate the environmental impact of floods (Wan and Billa, 2018). To adapt and mitigate decision-making and reduce disaster risk, Hosseini F. S. et al. proposed an improved integrated model of the generalized linear model and stochastic forest model (RF), which greatly facilitates the mapping of hazardous areas (Hosseini et al., 2020). Based on the Multicollinearity study and estimation of predictive power and information gain method, the study of Costache et al. revealed that the Multilayer Perceptron Statistical Index integration has the highest efficiency and is applied to the actual region mapping (Costache et al., 2020). The socio-economic vulnerability of flash floods was comprehensively assessed by Khajehei et al., and the main characteristics of flash floods, such as frequency, duration, severity, and magnitude, were investigated (Khajehei et al., 2020). Sezen et al. describe the process of developing computational risk assessment methods that incorporate the risks associated with earthquake and flood events into the traditional probabilistic risk assessment (Sezen et al., 2019) (Banda, 2019). To consider the main sources of uncertainty and quantify the confidence level of the results of a given design flood event, D'Oria et al. proposed a flood hazard mapping probability method, the method takes into account the uncertainty caused by the notch location and the failure time (D'Oria et al., 2019). Because of the serious impact of Ice Lake outburst flood on St area, Fan J et al. used mold and comprehensive evaluation method to evaluate ice lake investigation and ice lake ecosystem damage by nine indexes (Fan et al., 2019). Based on atmospheric, ground, and river parameters, Manna et al. built a model to predict the depth of submerged areas, estimated the vulnerability of each location, and assessed the range of risk levels (Manna et al., 2019). Moftak- 
hari et al. proposed and discussed a method combining bivariate statistical analysis with a hydrodynamic model for the general situation of flood disaster-related to upstream q-flow and downstream sea level (Moftakhari et al., 2019). To overcome this limitation, in which quantile estimates associated with periods of high returns are subject to significant uncertainty, Evin et al. proposed a new approach, 1) the combination of a classic series of observations with paleoclimate emissions from the reconstruction of open Lake sediments (Rhone River, Lake Bourget, Hida Mountains, France), and 2) the propagation of uncertainty associated with reconstruction methods during extreme quantile estimates (Evin et al., 2019). This study of Dou et al. elaborated a multi-parameter flood risk index (FHI) model for evaluating potential flood risk areas in Guanzhong Urban Area (GUA) (Dou et al., 2018). Xiao et al. combined geographic information system (GIS), fuzzy analytic hierarchy process (AHP), and spatially ordered weighted average method (OWA) to establish a multi-criteria analysis (MCA) framework for flood risk assessment (Xiao et al., 2017).

In addition to the improvement of the model and method, there is also a representation method through a flood hazard map. To draw a flood disaster map more effectively, Amirhossein ST et al. proposed a multi-index flood disaster classification method on Basin-scale, which is used to identify areas with high potential flood risk, and committed to more effective flood management and mitigation strategies (Toosi et al., 2019). Based on the concept of multi-method, Elsadek et al. evaluated the endangered area of Wadi Qena Basin by combining the morphometric ranking method and EI-Shamy method, and a comprehensive evaluation map reflecting the hazard degree of each sub-basin is constructed (Elsadek et al., 2019). H. Abdelkarim et al. used remote sensing (RS), GIS, hydrological model (water modeling system, WMS), hydraulic model (hydrological engineering center river analysis system, HEC-RAS) to evaluate the impact of flash floods on sustainable urban development in Tabuk City (KSA), Kingdom of Saudi Arabia (Abdelkarim et al., 2019). The combination of HSPF and Iber (Fonseca, AR, Santos, M, \& Santos, Ja) presented in this paper provides a basic tool for decision-makers to evaluate hydrological pairs for determining flood hazard maps (Fonseca et al., 2018). To provide an assessment of the risk, Salvadori et al. used a combination theory, failure probability, and a suitable test of nonparametric statistical change points (Salvadori et al., 2018). Andrade et al. combined AHP with flood hazard mapping to carry out a preliminary assessment of flood risk areas in the Napo River Basin in central Portugal (Andrade et al., 2018).

Some scholars also use the method of simulation and simulation to study the flood. Sepehril et al. used the constrained Delaunay triangular irregular network to model the good city surface (Sepehril et al., 2019). Bhat et al. used the RAS program of HEC to simulate its flow, water surface elevation, and spatial extent (Bhat et al., 2019a). Bhat et al. used advanced digital ground models and topographic maps of geographic information systems to determine the total flood level according to the composite value of the morphological parameters of each 
sub-basin (Bhat et al., 2019b). By using accurate, detailed and reliable digital terrain models (DTMs), Zazo et al. have generated more reliable river hazard maps to identify flood-prone areas (Zazo et al., 2018).

Of course, there are some other research directions, for example, Hajian et al. studied runoff changes in a small forest catchment area in northern Iran, and derived several land-use change scenarios and the effects of high rainfall and high previous soil moisture (Hajian et al., 2019). By using the two-dimensional and one-dimensional hydrodynamic simulation method, combined with the calculation and analysis of the golf hydrological curve, Sattar et al. discovered the settlement which may submerge both sides of the river (Sattar et al., 2019). Lyddon et al. used the interaction of tidal bore and the Spatio-temporal variability of combined flood disasters to assess the variability of the upper end of the estuary under extreme water levels (Lyddon et al., 2018).

In addition, the current data investigation methods, such as remote sensing and measured hydrological data, have relatively short data series, lack of data, and repeated information of multiple effect terms. Therefore, the current evaluation method is difficult to make a reasonable and effective evaluation. Therefore, we propose a gray correlation analysis method based on multiple information combinations to evaluate and classify the flood. In this paper, the gray correlation analysis method is used to establish a quantitative model, analyze the uncertain factors in the flood, and evaluate the flood disaster level and disaster loss in the Yellow River basin.

The research motivation of this paper is as follows: 1) The influence of qualitative and quantitative factors is considered. 2) This model of the paper is proposed from the perspective of post-disaster damage, rather than the perspective of flood hydrological characteristics. 3) A new flood classification evaluation model is proposed. And the main contributions of this paper are as follows: 1) With quantitative assessment, the degree of influence among different regions can be directly reflected by data. 2) The new flood comprehensive assessment model can be applied to forecast flood. It has certain guiding significance to the flood control in this area in the future and the advanced deployment of manpower, material resources, and financial resources. 3) Data collection is convenient, which helps to save costs.

The rest of the paper is structured as follows: Section 2 gives a brief introduction to the gray correlation analysis method. Section 3 presents the construction of assumptions and models. In section 4, the proposed model is introduced into practical cases for application simulation, and the existing national flood assessment standards are compared with this method. Part 5 summarizes some of the conclusions.

\section{Preliminaries}

Since the gray system was established by professor Deng Julong in 1982, many systems analysis methods based on gray system theory have been put forward after years of development. Gray relational analysis is the theoretical basis of 
gray system prediction and analysis. The higher the similarity of variation trend between the two factors, the higher the degree of correlation between them, and vice versa. Gray correlation analysis is simple in the calculation, clear in order, and does not need to make special assumptions about data distribution. Gray relational analysis is an analytical method of gray system theory, which is applicable to systems with known information. The mathematical model of gray relation is given.

In some systems, due to the lack of information, incomplete information, and uncertainty, it is difficult for us to judge the relationship between elements and distinguish between the primary and secondary factors. The purpose of the gray correlation analysis is to analyze such a system and use the quantization and sequence transformation between system factors to analyze the development trend of the system expressed by uncertain data.

1) Determine the reference sequence reflecting the behavior characteristics of the system and the comparison sequence affecting the behavior of the system.

2) Dimensionless processing of reference and comparison sequences.

3) The gray relational coefficient of the reference series and the comparative series.

4) To find the correlation degree.

5) Correlation degree ordering.

\section{Mode Building}

\subsection{Parameters and Assumptions}

There are many uncertain factors influencing the grading assessment of flood. In China, the main evaluation criteria are mainly controlled by three key indicators. These sections will be discussed next.

1) Disaster area mainly refers to the crop disaster area (including crop disaster area and crop failure area). Unit: Per 10,000 hectares $\left(10,000 \mathrm{hm}^{2}\right)$.

2) Social indicators: affected population. Unit: Every 10,000 people.

3) Property index: collapsed and damaged houses. Unit: Every 10,000 houses.

\subsection{Classification of Flood Disaster Based on Gray Correlation Analysis}

\subsubsection{Determine the Reference Sequence and the Comparison Sequence}

Determine the reference sequence reflecting system behavior characteristics and the comparison sequence affecting system behavior.

The reference number is listed as: $X_{0}^{(k)}=\left[x_{0}^{(1)}, x_{0}^{(2)}, x_{0}^{(3)}\right]=[1,1,1]$

Among them, the value of the conversion function of each single grading index of the reference sequence is 1 , that is, it represents the extremely serious disaster of the standard.

The comparison number is listed as: $X_{i}^{(k)}=\left[x_{i}^{(1)}, x_{i}^{(2)}, x_{i}^{(3)}\right]$

$X$ represents the region " $X$ "; $i$ means area " $i$ "; $k$ is the factor " $k$ ". 


\subsubsection{Dimensionless Processing of Reference and Comparison Sequences}

Due to the different physical meanings and measurement units of each indicator, the data dimensions are different, which makes it difficult to carry out between different orders of magnitude. Therefore, according to the gray principle, in order to facilitate the analysis, it is necessary to normalize the original data before the comparison of various factors, so as to unify the reclassification standards of different indicators. Therefore, the corresponding function conversion is made for the classification indicators first. The conversion function is as follows:

1) The conversion function of the affected area

$$
X_{i}^{\left(k^{\prime}\right)}=\left\{\begin{array}{lc}
1 & 10^{6}<X \\
\frac{1}{3} \lg \frac{X}{10^{3}} & 10^{3}<X \leq 10^{6} \\
0 & X \leq 10^{3}
\end{array}\right.
$$

2) The conversion function of the affected population

$$
X_{i}^{\left(k^{\prime}\right)}=\left\{\begin{array}{lc}
1 & 3 \times 10^{7}<X \\
\frac{1}{\lg 30000} \lg \frac{X}{10^{3}} & 10^{3}<X \leq 3 \times 10^{7} \\
0 & X \leq 10^{3}
\end{array}\right.
$$

3) The conversion function of collapsed damaged houses

$$
X_{i}^{\left(k^{\prime}\right)}=\left\{\begin{array}{lc}
1 & 8 \times 10^{5}<X \\
\frac{1}{\lg 800} \lg \frac{X}{10^{3}} & 10^{3}<X \leq 8 \times 10^{5} \\
0 & X \leq 10^{3}
\end{array}\right.
$$

\subsubsection{Find the Gray Correlation Coefficient between the Reference Sequence and the Comparison Sequence}

$$
\begin{gathered}
\Delta_{i}(k)=\left|X_{0}^{\left(k^{\prime}\right)}-X_{i}^{\left(k^{\prime}\right)}\right| \\
\xi\left(X_{i}\right)=\frac{\min _{i} \min _{k}\left|\Delta_{i}(k)\right|+\rho \max _{i} \max _{k}\left|\Delta_{i}(k)\right|}{\Delta_{i}(k)+\rho \max _{i} \max _{k}\left|\Delta_{i}(k)\right|}
\end{gathered}
$$

Type of $\Delta$ is the absolute difference between the reference sequence and the compared sequence. The higher this value was, the lower the correlation degree $\xi$ $\left(X_{i}\right)$ is; On the contrary, the correlation is greater. $\rho$ is called the discrimination coefficient and is often taken $\rho=0.5$.

\subsubsection{Seek Disaster Correlation Degree}

Equal weight average method is adopted.

$$
r_{i}=\frac{1}{3} \sum_{j}^{3} \xi\left(X_{i}\right)
$$

The correlation degree can reflect the severity of the disaster, so the correlation degree can be used to reflect the severity of the disaster and classify the dis- 
aster.

The disaster correlation degree is the result of the comprehensive evaluation of three values. As you can see, if $\left|\Delta_{i}(k)\right|=\min \min \left|\Delta_{i}(k)\right|$, then $\xi\left(X_{i}\right)=1$;

If $\left|\Delta_{i}(k)\right|=\max \max \left|\Delta_{i}(k)\right|$, then $\xi\left(X_{i}\right) \stackrel{i}{=} 0$; When $\min _{i} \min _{k}\left|\Delta_{i}(k)\right|<\left|\Delta_{i}(k)\right|<\max _{i} \max _{k}\left|\Delta_{i}(k)\right|, \quad 0<\xi\left(X_{i}\right)<1$. Therefore, the value range of disaster correlation degree is $0-1$.

\subsubsection{Ranking of Correlation Degree}

According to the classification index and classification standard of flood disasters previously provided, the following classification interval is made. The numbers 1 to 5 correspond to five degrees of flood impact ( 1 is the most severely affected and 5 is the least affected). The flood rating range is shown in Table 1.

Table 1 . The flood rating range.

\begin{tabular}{|c|c|c|c|c|c|}
\hline \multicolumn{6}{|c|}{ Severity } \\
\hline & Extremely & Very & More & Slightly & Merely \\
\hline & Serious (1) & Serious (2) & Serious (3) & Serous (4) & Serious (5) \\
\hline$r_{i}$ & $1-0.8$ & $0.8-0.6$ & $0.6-0.4$ & $0.4-0.2$ & $0.2-0$ \\
\hline
\end{tabular}

Table 2. Statistical table of affected area $\left(10,000 \mathrm{hm}^{2}\right)$.

\begin{tabular}{cccccccccc}
\hline & \multicolumn{8}{c}{ Province } \\
\cline { 2 - 9 } & \multicolumn{10}{c}{ Sichuan Qinghai } & Gansu & Ningxia & $\begin{array}{c}\text { Inner } \\
\text { Mongolia }\end{array}$ & $\begin{array}{c}\text { Shanxi } \\
(\text { SN })\end{array}$ & $\begin{array}{c}\text { Shaanxi } \\
(\text { SX) }\end{array}$ & Henan Shandong \\
\hline 2011 & 62.1 & 3.1 & 11.8 & 0.9 & 52 & 43.5 & 26.3 & 29.7 & 29.8 \\
2012 & 66.9 & 3.8 & 22.9 & 6.6 & 125 & 23.7 & 30.9 & 37.8 & 34.2 \\
2013 & 66.2 & 1.6 & 30.1 & 6 & 68 & 24.8 & 16.4 & 6.2 & 104.2 \\
Year 2014 & 34.5 & 1.7 & 16.3 & 0.2 & 10.2 & 17 & 10.4 & 5.2 & 6.7 \\
2015 & 29.1 & 1.4 & 8.8 & 0.7 & 20.6 & 11.1 & 3.8 & 5.6 & 24.7 \\
2016 & 16.3 & 1.6 & 12.3 & 1.6 & 27.1 & 11.5 & 27.4 & 24.5 & 11.2 \\
& 16.7 & 0.6 & 9.4 & 0.9 & 25.6 & 9.9 & 5.8 & 98.8 & 6.9 \\
\hline
\end{tabular}

Table 3. Affected population (Every 10,000 people).

\begin{tabular}{|c|c|c|c|c|c|c|c|c|c|c|}
\hline & & \multicolumn{9}{|c|}{ Province } \\
\hline & & Sichuan & Qinghai & Gansu & Ningxia & $\begin{array}{c}\text { Inner } \\
\text { Mongolia }\end{array}$ & $\begin{array}{c}\text { Shanxi } \\
(\mathrm{SN})\end{array}$ & $\begin{array}{c}\text { Shaanxi } \\
\text { (SX) }\end{array}$ & Henan & Shandong \\
\hline \multirow{7}{*}{ Year } & 2011 & 2253.4 & 26.7 & 154.8 & 0.4 & 138.3 & 685.4 & 235.2 & 937.9 & 935.8 \\
\hline & 2012 & 2955.4 & 49.7 & 273.3 & 32.5 & 222.4 & 355.9 & 252 & 499.5 & 587.4 \\
\hline & 2013 & 2113.7 & 8.6 & 422.2 & 45.8 & 164.2 & 320.6 & 344.3 & 484.6 & 803.9 \\
\hline & 2014 & 902.2 & 14.9 & 167.9 & 2.5 & 13.1 & 186.6 & 65.1 & 63.8 & 85.6 \\
\hline & 2015 & 677 & 11.5 & 69.9 & 2.1 & 49.6 & 86.9 & 30.5 & 59.6 & 191 \\
\hline & 2016 & 327.6 & 10.9 & 86.9 & 7.2 & 76.1 & 99.2 & 283.8 & 316.9 & 154.2 \\
\hline & 2017 & 335.2 & 4.9 & 111.7 & 24.7 & 78.1 & 160.7 & 117.1 & 1024.5 & 93.5 \\
\hline
\end{tabular}


Table 4. Collapsed and damaged houses (Every 10,000 houses).

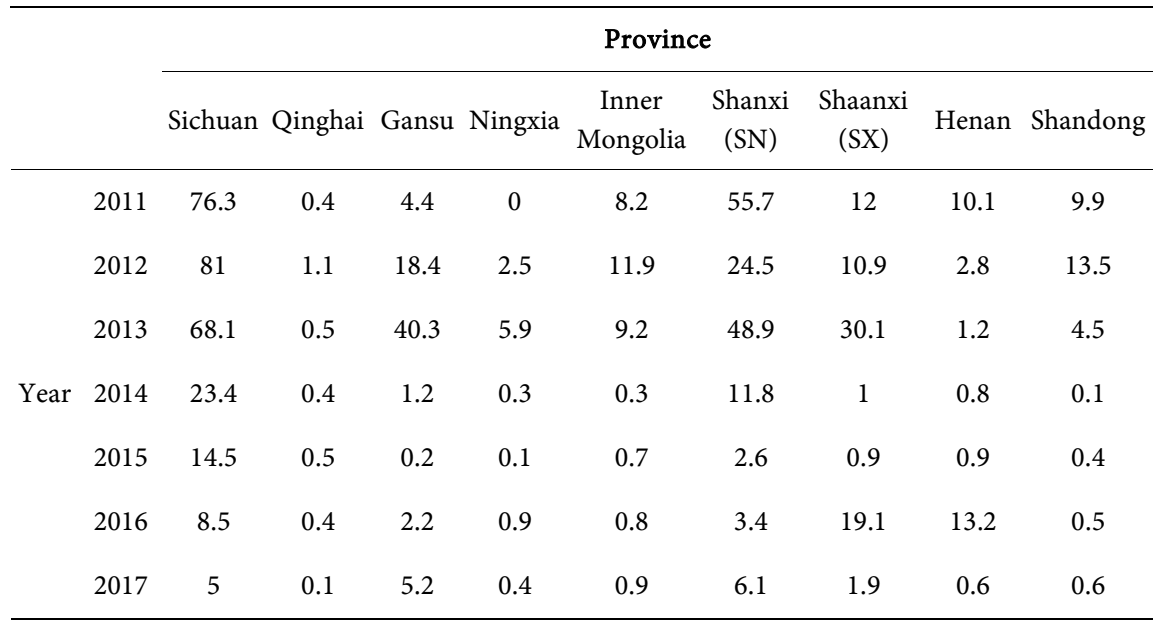

Table 5. Disaster levels in each region.

\begin{tabular}{lccccccccc}
\hline region & Sichuan & Qinghai & Gansu & Ningxia & $\begin{array}{c}\text { Inner } \\
\text { Mongolia }\end{array}$ & $\begin{array}{c}\text { Shanxi } \\
(\mathrm{SN})\end{array}$ & $\begin{array}{c}\text { Shaanxi } \\
(\mathrm{SX})\end{array}$ & Henan Shandong \\
\hline $\begin{array}{c}\text { Disaster } \\
\text { grade }\end{array}$ & 2 & 1 & 2 & 1 & 2 & 2 & 1 & 2 & 2 \\
\hline
\end{tabular}

\section{A Case Study}

Flood control in the Yellow River Basin has always been the most important task. According to historical meteorological data statistics, the average annual precipitation in the Yellow River Basin reached $448 \mathrm{~mm}$ (1961-2010), and the rainfall in summer accounted for more than half of the annual rainfall, of which the rainfall in July and August accounted for about $40 \%$ of the annual rainfall. Yue Zhongming, director of the Yellow River Water Conservancy Commission under the Ministry of Water Resources, said that the Yellow River has not seen a flood of more than 10,000 cubic meters per second for 36 years. "After a long drought, there will be a flood", he said.

Therefore, it is very important to assess the flood risk in different areas of the Yellow River basin and allocate manpower and material resources reasonably and effectively according to the assessment results.

The data are from the China Meteorological Disaster Yearbook. This paper collects three types of data related to the flood (including the statistical table of the affected area, affected population, and direct economic losses), and the relevant data of the three types of data from 9 provinces across the Yellow River basin from 2011 to 2017. These data will be shown in Tables 1-4 in the article.

\subsection{Result of the Novel Mode}

Finally, the RI value is obtained after the data is brought into the model for calculation. 


$$
\bar{r}_{i}=\left(\begin{array}{lllllllll}
0.60 & 0.89 & 0.81 & 0.82 & 0.77 & 0.78 & 0.85 & 0.72 & 0.71
\end{array}\right)
$$

Then compare with the flood disaster classification index and classification standard to get the flood disaster classification of each region in the above Table 5.

\subsection{Comparing Summary}

\subsubsection{Existing Flood Classification Methods}

According to the National Standard Hydrologic Information Forecast Code "GB/T 22482-2008", which came into effect on 1 January 2009, floods can be classified into four classes

1) A flood whose recurrence period of flood elements is less than 5 years is a minor flood;

2) The flood whose recurrence period of flood elements is 5 to 20 years is medium flood;

3) The flood whose recurring period of flood elements is 20 to 50 years is a major flood;

4) A flood whose recurrence period of flood elements is greater than 50 years is a catastrophic flood.

Hydrological elements in the estimation of the recurrence period include peak flood level or maximum flood volume in the period, etc., which can be selected according to the hydrological characteristics of the river.

\subsubsection{Improved Flood Rating Criteria}

Through the calculation and analysis of the relevant data of nine provinces in the Yellow River Basin from 2011 to 2017, the corresponding correlation between the correlation degree of each province and the disaster level in the below Table 6 is obtained.

It can be seen that Qinghai, Ningxia, and Shanxi are divided into extremely severe disasters according to the calculation. And then compared through correlation degree, the disaster situation was divided into: Qinghai > Ningxia > Shanxi (From severe to mild); According to the calculation, Sichuan, Gansu, Inner Mongolia, Shaanxi, Henan, and Shandong were divided into severe disasters. By comparing the correlation degree, the disaster situations were divided into: Shaanxi $>$ Gansu $>$ Inner Mongolia $>$ Shandong $>$ Henan $>$ Sichuan province (From severe to mild).

Table 6. Table of correlation degree and disaster grade of each province.

\begin{tabular}{|c|c|c|c|c|c|c|c|c|c|}
\hline region & Sichuan & Qinghai & Gansu & Ningxia & $\begin{array}{c}\text { Inner } \\
\text { Mongolia }\end{array}$ & $\begin{array}{c}\text { Shanxi } \\
(\mathrm{SN})\end{array}$ & $\begin{array}{l}\text { Shaanxi } \\
\text { (SX) }\end{array}$ & Henan & Shandong \\
\hline $\begin{array}{c}\text { Disaster } \\
\text { grade }\end{array}$ & 2 & 1 & 2 & 1 & 2 & 2 & 1 & 2 & 2 \\
\hline$\overline{r_{i}}$ & 0.65 & 0.88 & 0.75 & 0.85 & 0.72 & 0.76 & 0.82 & 0.67 & 0.69 \\
\hline
\end{tabular}




\section{Conclusion}

The reasonable evaluation and grading of the flood play an important role in the emergency layout of the flood disaster in the future. Combined with the gray correlation analysis, it can be analyzed in accordance with the development trend. At the same time, it is also the most important point. The gray correlation analysis has no specific requirements on the number of sample size, and at the same time, it does not need typical distribution rules, which can save a lot of calculation and obtain qualitative analysis results. By combining the data from 2011 to 2017, we can draw the following conclusions:

1) Compared with the previous flood classification method, a new method by real-time hydrological factors to evaluate the relevant data, through the usual data since, analyze the relevant data, to draw a rough future flood rating, allowing to monitor the region ahead of time, reduce the consumption of a large amount of manpower material resources.

2) This method requires the truth and objectivity of objective data. The gray level processing method requires a certain degree of subjective judgment. The combination of the two makes the subjectivity of the gray level comprehensive to a certain extent.

\section{Acknowledgements}

This work was supported by the National Natural Science Foundations of China (Grant No. 71771157), and funding from Sichuan University (Grant No. skqx201726), China Postdoctoral Science Foundation Funded Project (Grant No. 2017M610609), and Soft Science Program of Sichuan Province (Grant No. 2019JDR0129).

\section{Conflicts of Interest}

The author declares no conflicts of interest regarding the publication of this paper.

\section{References}

Abdelkarim, A., Gaber, A. F. D., Youssef, A. M., \& Pradhan, B. (2019). Flood Hazard Assessment of the Urban Area of Tabuk City, Kingdom of Saudi Arabia by Integrating Spatial-Based Hydrologic and Hydrodynamic Modeling. Sensors, 19. https://doi.org/10.3390/s19051024

Andrade, C., Rodrigues, S., \& Corte-Real, J. A. (2018). Preliminary Assessment of Flood Hazard in Nabao River Basin Using an Analytical Hierarchy Process. International Conference of Numerical Analysis and Applied Mathematics (ICNAAM 2017), 1978. https://doi.org/10.1063/1.5043854

Banda, W. (2019). An Integrated Framework Comprising of AHP, Expert Questionnaire Survey and Sensitivity Analysis for Risk Assessment in Mining Projects. International Journal of Management Science and Engineering Management, 14, 180-192. https://doi.org/10.1080/17509653.2018.1516577

Bhat, M. S., Ahmad, B., Alam, A., Farooq, H., \& Ahmad, S. (2019a). Flood Hazard Assessment of the Kashmir Valley Using Historical Hydrology. Journal of Flood Risk 
Management, 12. https://doi.org/10.1111/jfr3.12521

Bhat, M. S., Alam, A., Ahmad, S., Farooq, H., \& Ahmad, B. (2019b). Flood Hazard Assessment of Upper Jhelum Basin Using Morphometric Parameters. Environmental Earth Sciences, 78. https://doi.org/10.1007/s12665-019-8046-1

Costache, R., Hong, H. Y., \& Pham, Q. B. (2020). Comparative Assessment of the Flash-Flood Potential within Small Mountain Catchments Using Bivariate Statistics and Their Novel Hybrid Integration with Machine Learning Models. Science of the Total Environment, 711. https://doi.org/10.1016/j.scitotenv.2019.134514

D’Oria, M., Maranzoni, A., \& Mazzoleni, M. (2019). Probabilistic Assessment of Flood Hazard Due to Levee Breaches Using Fragility Functions. Water Resources Research, 55, 8740-8764. https://doi.org/10.1029/2019WR025369

Dou, X. Y. et al. (2018). Flood Risk Assessment and Mapping Based on a Modified Multi-Parameter Flood Hazard Index Model in the Guanzhong Urban Area, China. Stochastic Environmental Research and Risk Assessment, 32, 1131-1146. https://doi.org/10.1007/s00477-017-1429-5

Elsadek, W. M., Ibrahim, M. G., Mahmod, W. E., \& Kanae, S. (2019). Developing an Overall Assessment Map for Flood Hazard on Large Area Watershed Using Multi-Method Approach: Case Study of Wadi Qena Watershed, Egypt. Natural Hazards, 95, 739-767. https://doi.org/10.1007/s11069-018-3517-3

Evin, G., Wilhelm, B., \& Jenny, J. P. (2019). Flood Hazard Assessment of the Rhone River Revisited with Reconstructed Discharges from Lake Sediments. Global and Planetary Change, 172, 114-123. https://doi.org/10.1016/j.gloplacha.2018.09.010

Fan, J. R., An, C. C., Zhang, X. Y., Li, X., \& Tan, J. J. (2019). Hazard Assessment of Glacial Lake Outburst Floods in Southeast Tibet Based on RS and GIS Technologies. International Journal of Remote Sensing, 40, 4955-4979. https://doi.org/10.1080/01431161.2019.1577578

Fonseca, A. R., Santos, M., \& Santos, J. A. (2018). Hydrological and Flood Hazard Assessment Using a Coupled Modelling Approach for a Mountainous Catchment in Portugal. Stochastic Environmental Research and Risk Assessment, 32, 2165-2177. https://doi.org/10.1007/s00477-018-1525-1

Hajian, F., Dykes, A. P., \& Cavanagh, S. (2019). Assessment of the Flood Hazard Arising From Land Use Change in a Forested Catchment in Northern Iran. Journal of Flood Risk Management, 12. https://doi.org/10.1111/jfr3.12481

Hosseini, F. S. et al. (2020). Flash-Flood Hazard Assessment Using Ensembles and Bayesian-Based Machine Learning Models: Application of the Simulated Annealing Feature Selection Method. Science of the Total Environment, 711.

https://doi.org/10.1016/j.scitotenv.2019.135161

Khajehei, S., Ahmadalipour, A., Shao, W. Y., \& Moradkhani, H. (2020). A Place-Based Assessment of Flash Flood Hazard and Vulnerability in the Contiguous United States. Scientific Reports, 10. https://doi.org/10.1038/s41598-019-57349-Z

Lyddon, C., Brown, J. M., Leonardi, N., \& Plater, A. J. (2018). Flood Hazard Assessment for a Hyper-Tidal Estuary as a Function of Tide-Surge-Morphology Interaction. Estuar Coast, 41, 1565-1586. https://doi.org/10.1007/s12237-018-0384-9

Manna, P., Anis, M. Z., Das, P., \& Banerjee, S. (2019). Probabilistic Modeling of Flood Hazard and Its Risk Assessment for Eastern Region of India. Risk Analysis, 39, 1615-1633. https://doi.org/10.1111/risa.13333

Moftakhari, H., Schubert, J. E., AghaKouchak, A., Matthew, R. A., \& Sanders, B. F. (2019). Linking Statistical and Hydrodynamic Modeling for Compound Flood Hazard Assessment in Tidal Channels and Estuaries. Advances in Water Resources, 128, 28-38. 
https://doi.org/10.1016/j.advwatres.2019.04.009

Press, C. M. (2019). Yearbook of Meteorological Disasters in China.

Salvadori, G., Durante, F., De Michele, C., \& Bernardi, M. (2018). Hazard Assessment under Multivariate Distributional Change-Points: Guidelines and a Flood Case Study. Water, 10. https://doi.org/10.3390/w10060751

Sattar, A., Goswami, A., \& Kulkarni, A. V. (2019). Hydrodynamic Moraine-Breach Modeling and Outburst Flood Routing-A Hazard Assessment of the South Lhonak Lake, Sikkim. Science of the Total Environment, 668, 362-378.

https://doi.org/10.1016/j.scitotenv.2019.02.388

Sepehril, M., Malekinezhad, H., Hosseini, S. Z., \& Ildoromi, A. R. (2019). Assessment of Flood Hazard Mapping in Urban Areas Using Entropy Weighting Method: A Case Study in Hamadan City, Iran. Acta Geophysica, 67, 1435-1449.

https://doi.org/10.1007/s11600-019-00342-x

Sezen, H., Hur, J., Smith, C., Aldemir, T., \& Denning, R. (2019). A Computational Risk Assessment Approach to the Integration of Seismic and Flooding Hazards with Internal Hazards. Nuclear Engineering and Design, 355.

https://doi.org/10.1016/j.nucengdes.2019.110341

Toosi, A. S., Calbimonte, G. H., Nouri, H., \& Alaghmand, S. (2019). River Basin-Scale Flood Hazard Assessment Using a Modified Multi-Criteria Decision Analysis Approach: A Case Study. Journal of Hydrology, 574, 660-671. https://doi.org/10.1016/j.jhydrol.2019.04.072

Wan, K. M., \& Billa, L. (2018). Post-Flood Land Use Damage Estimation Using Improved Normalized Difference Flood Index (NDFI3) on Landsat 8 Datasets: December 2014 Floods, Kelantan, Malaysia. Arab J Geosci, 11. https://doi.org/10.1007/s12517-018-3775-0

Xiao, Y. F., Yi, S. Z., \& Tang, Z. Q. (2017). Integrated Flood Hazard Assessment Based on Spatial Ordered Weighted Averaging Method Considering Spatial Heterogeneity of Risk Preference. Science of the Total Environment, 599, 1034-1046. https://doi.org/10.1016/j.scitotenv.2017.04.218

Zazo, S. et al. (2018). Flood Hazard Assessment Supported by Reduced Cost Aerial Precision Photogrammetry. Remote Sensing, 10. https://doi.org/10.3390/rs10101566 